\title{
UNUSUAL BARN SWALLOW NEST SITE
}

\section{DALE HJERTAAS, 15 Olson Place, Regina, Saskatchewan. S4S $2 J 6$}

I usually like to fill out a nest record card for each bird nest I locate. However, I had a problem filling out the card for a Barn Swallow nest in Coalfield's PFRA community pasture on 6 June 1990 . Height above ground was the difficulty; I finally noted "varies from 10 to 14 feet."

Frank Switzer, Keith Barr and I were censusing birds in this pasture east of Estevan when we noticed two Barn Swallows flying around an oil pumping unit. As it was several miles to any building, I felt the swallows must be nesting on the pumping unit. A search around the frame and engine housing revealed nothing. Then I watched a Barn Swallow fly to the pump head. Where the head attached to the huge pivoting beam which tilts back and forth to lift the oil was a nice sheltered ledge, ideal for a Bam Swallow nest, except that it was constantly moving up and down and the angle of the beam was changing constantly. Nonetheless the Barn Swallow was busily working on a $75 \%$ completed nest, apparently perfectly satisfied with a moving platform.

At the oil pumping unit on the next LSD we were surprised to notice a second pair of Barn Swallows building their nest on the same sheltered ledge at the pump head. Later that day, while Keith Barr and I were returning to Regina we stopped at an oil well site near Weyburn and noted an old Barn Swallow nest on the head of this oil pump. However, we have no way of knowing whether the pump was active in the year the nest was built.

Could these swallows have started their nests during a temporary shutdown of the wells or has a local tradition developed of using the moving pump heads due to the total lack of other suitable nest sites? The fact the Bam Swallows were building while the pump head moved suggests they were willing to start and build on the active pump. However, it is possible that the first nestings on these pumps could have occurred on a shutdown pump. Once the image of the pump head as a suitable site developed, its use may have spread to active pumps.

Would constant shifting have an impact on the eggs and chicks? Unfortunately, I was not able to revisit the area and so do not know if either nest was successful. 